\title{
Component failures based on flaw distributions
}

\author{
Jensen, Finn
}

Published in:

Proceedings of the Annual Reliability and Maintainability Symposium

Link to article, DOI:

10.1109/ARMS.1989.49581

Publication date:

1989

Document Version

Publisher's PDF, also known as Version of record

Link back to DTU Orbit

Citation (APA):

Jensen, F. (1989). Component failures based on flaw distributions. In Proceedings of the Annual Reliability and Maintainability Symposium (pp. 91-95). IEEE. https://doi.org/10.1109/ARMS.1989.49581

\section{General rights}

Copyright and moral rights for the publications made accessible in the public portal are retained by the authors and/or other copyright owners and it is a condition of accessing publications that users recognise and abide by the legal requirements associated with these rights.

- Users may download and print one copy of any publication from the public portal for the purpose of private study or research.

- You may not further distribute the material or use it for any profit-making activity or commercial gain

- You may freely distribute the URL identifying the publication in the public portal

If you believe that this document breaches copyright please contact us providing details, and we will remove access to the work immediately and investigate your claim. 
Finn Jensen; The Engineering Academy of Denmark; Lyngby

Key Words: Failure-freak, Failure mechanism, Failure rate model, Flaw, Life distribution.

\section{Abstract}

Much recent interest in component reliability has been concerned with establishing a logical basis for why component patterns in general follow a bath-tub, or modified bath-tub (sometimes called a "roller-coaster"), type of curve.

This paper discusses a model based on the assumption that all failures basically are due to wearout. The only real difference between long-term wearout and the failures that occur in early life and during the useful life period will be in the size of the inherent flaws or defects in the component. Large flaws connect with early life failures, small flaws connect with end-of-life-failures.

The model takes several competing failure mechanisms into account. Examples and case studies are used to provide substance to the model.

\section{Introduction}

The viewpoint taken in this paper is that all failures in components working under a fixed set of operating and environmental conditions are due to wearout. This statement uses the word wearout in a broad sense. Wearout describes the deterioration in component strength that takes place when a component is subjected to a constant or time changing load. We can use the terms wearout and deterioration synonymously. Wearout will thus encompass the following two processes:

- wear itself is the cumulative damage brought about by processes which actually remove material from a component or component substructure. Automobile tyres wear, as do electronic vacuum tubes, and metallization lines in integrated circuits through corrosion or electromigration.

- fatigue involves the application of fluctuating loads over a period of time. Failure takes place by the initiation and propagation of a crack. There is no removal of material involved. Solder joints experience fatigue when subjected to thermal cycling or vibration.

Note that we confine the present discussion to situations in which the operating and environmental conditions are constant (or changing in a predetermined cyclic manner), as will typically be the case during a lifetest. The situation changes significantly if the components are in a working system environment where random stresses and overloads may be expected. In such cases it is relatively easy, for example, to argue for a constant hazard rate in the useful life period (see for example Kapur and Lamberson, 1977).

Further, it must be recognized that a component may fail due to one of several failure mechanisms. For example, integrated circuits may typically display the following failure mechanisms:

$$
\begin{aligned}
& \text { - electromigration } \\
& \text { - oxide breakdown } \\
& \text { - ionic drift } \\
& \text { - bonding } \\
& \text { - corrosion }
\end{aligned}
$$

The list is of course far from complete. The "Microelectronics Failure Analysis Techniques", 1982, mentions no less that 55 failure mechanisms, while the ESS "Environmental Stress Screening Guidelines for Parts", 1985, includes 30 integrated circuit failure mechanisms.

In a "perfect" component, utilized within its capabilities as regards current, voltage, and temperature, failures will not occur. It is the presence of imperfections, or flaws, in a "practical" component that will lead to failure under normal operating conditions. It is reasonable to suggest that the wearout or deterioration in component strength is the result of flaw growth. The following sections will elaborate on this assumption and describe the connection between lifetimes of flaws and the lifetime pattern of the component concerned.

The concept of component failures being due to a wearout process not only for end-of-life failures but also for early and mid-life failures has previously been described in the literature (see for example Pitetti, 1972; Mead, 1975; Nash et.al, 1985; Gerling, 1985; INTEL, 1986; Wong and Lindstrom, 1988).

Strength deterioration and the lifetime patterns of flaws

A component will fail whenever the load or stress on the component is greater than its strength (Carter, 1986). The larger the flaw, the lower will be the strength. Figure 1 shows a load distribution, and the bimodal strength distribution of a particular component type. The weak subpopulation of the component illustrated here is normally attributed to processing or workmanship failures. For a well controlled production line only the main or strong population will exist.

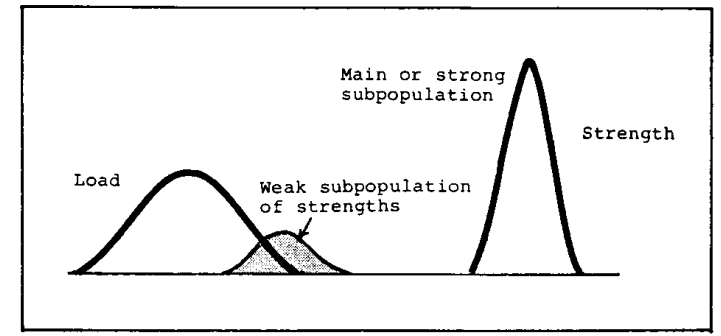

Fig. 1. A bimodal strength distribution results when the manufacturing process generates a small amount of sub-standard strengths, the weak subpopulation.

Most failures in electronic components arise from physical or chemical processes that cause deterioration of the inherent strength of the component. We will for the time being consider just a single flaw type or failure mechanism. To model the strength deterioration it is assumed that the deterioration processes are governed by differential equations involving time (Bosch, 1979; Jensen, et.al., 1989). In the simple cases this leads to strength deterioration curves such as shown in Figure 2.

Consider now the situation shown in Figure 3 . On the strength axis, a mixed distribution of a weak and a strong subpopulation is shown. We assume further that we are dealing with a single value of the load as in a typical lifetest experiment. The lifetime or time to failure density distribution function, $g(t)$, is computed by recognizing that failures occur when the strength has degraded to the value of the load, L. The cross hatched area under the two distribution curves must be the same. The mathematics leading to the derivation of the $\mathrm{g}(\mathrm{t})$ curve is then quite straightforward (Jensen et. al., 1989). 

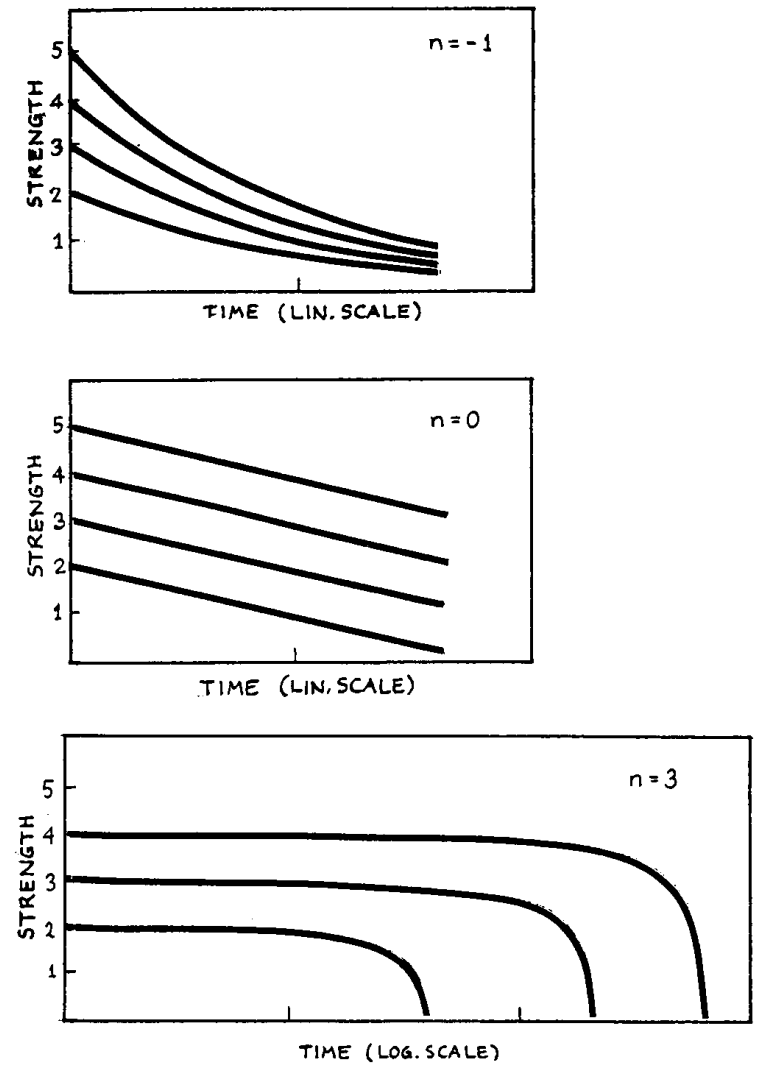

Fig. 2. Examples of strength deterioration curves.

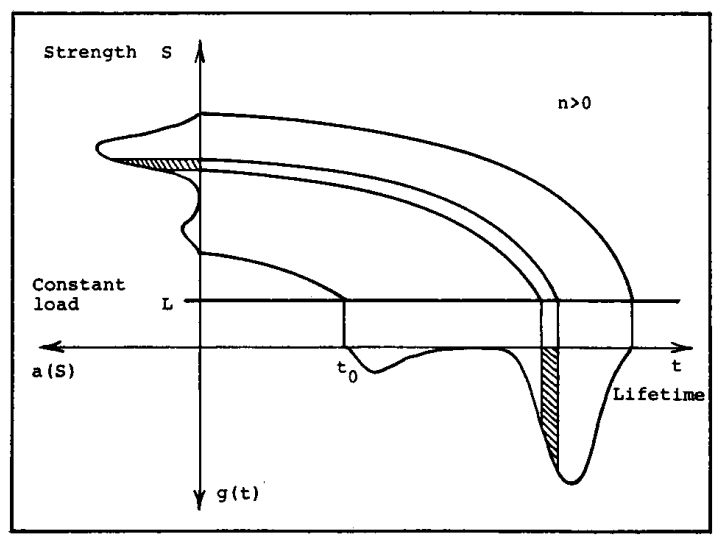

Fig. 3. The generation of a lifetime pattern from a strength distribution and its deterioration.

\section{Lifetime patterns of components}

The previous section shows how a failure distribution for a particular flaw type can be derived by modelling the flaw growth or strength deterioration. In this section we introduce some basic statistical theory that will help us understand the more complex situation of several different failure mechanisms present in any particular component.
Consider first Figure 4. This is a symbolic representation of a component with four different failure mechanisms but there is only one flaw of each type. When a load is applied to the component each flaw will "generate" a specific lifetime that is independent of the other flaws. In effect, $k=4$ different lifetimes $x_{1}, x_{2}, x_{3}$, and $x_{4}$ start simultaneously.

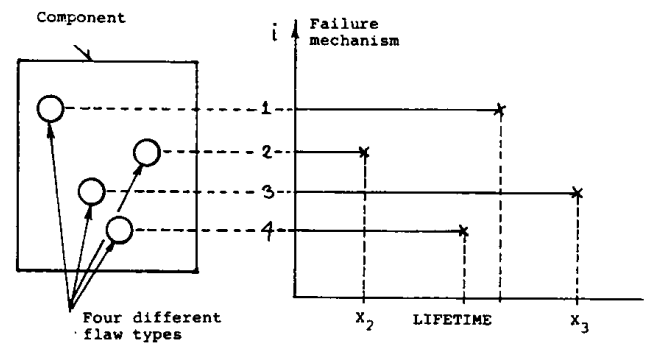

Fig. 4. A component with $k=4$ flaws. Each flaw has an associated failure mechanism. Each flaw generates a certain lifetime denoted $x_{1}, x_{2}, x_{3}$, and $x_{4}$. The component lifetime in this example is $\mathrm{X}=\mathrm{X}_{2}$.

The lifetime of the component will of course be the smallest of the flaw lifetimes. If we denote the component lifetime by the variable $X$, then

$$
X=X_{(1)}=\min \left(X_{1}, X_{2}, X_{3}, \ldots . ., X_{k}\right)
$$

This model is sometimes termed the competing risk model. The probability of a component surviving flaw type $\mathrm{i}$, at time $\mathrm{t}$, is

$$
R_{i}(t)=P\left(X_{i}>t\right)=1-G_{i}(t),
$$

where $G_{i}(t)$ is the distribution function of lifetimes for flaw type i. We now use the assumption that the failure mechanisms develop independently of one another.

The probability of surviving all $k$ failure mechanisms at time $t$ is

$$
\underset{i=1}{k}\left(1-G_{i}(t)\right) \text {, }
$$

and the distribution function of component failures (lifetimes) is

$$
F(t)=1-\prod_{i=1}^{k}\left(1-G_{i}(t)\right)
$$

This formula is valid quite generally whether there is only one flaw of each type, or several flaws. However, we need to elaborate a little on the situation (most plausible) where there are several flaws of each type. This is illustrated in Figure 5. The component lifetime will of course still be the shortest of all possible lifetimes.

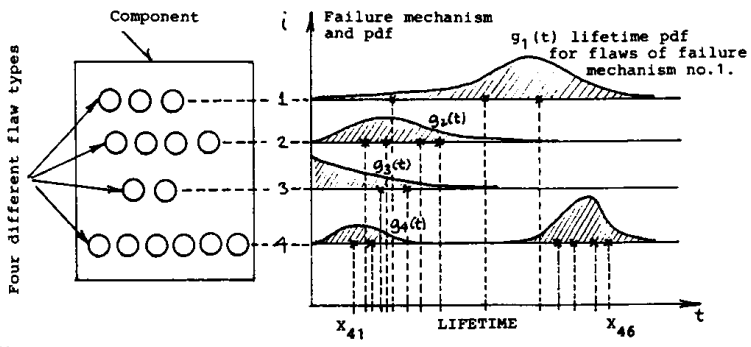

Fig. 5. A component with several flaws of each type $k=1$ through 4. The distributions of the lifetimes of the individual failure mechanisms are shown on the right hand side. The component lifetime is $\mathrm{X}=\mathrm{X}_{41}$. 
Consider a single flaw type, $\mathrm{i}$, and its associated failure mechanism. Let there be $\mathrm{N}_{\mathrm{i}}$ flaws of this particular type The flaws will be of varying severity, and each separate flaw will develop a specific lifetime $x_{i 1}, x_{i 2}, \ldots, x_{i N i}$ under the influence of the operating conditions. The cumulative distribution function of these lifetimes is denoted $G_{i}(t)$. Disregarding for the time being the other competing failure mechanisms, the flaw of major concern is the one that leads to the earliest failure. The random variable for the shortest lifetime of failure mechanism $i$ is the random variable $X_{i}(1)$ with cumulative distribution function $F_{X i}(t)$. This is the distribution of the first order statistic. It may easily be shown (see for example Mann, et.al., 1974) that the distribution function for the smallest value of a random sample of size $N_{i}$ is given by

$$
P\left(X_{i} \leq(t)=F_{X i}(t)=1-\left(1-G_{i}(t)\right)^{N_{i}}\right.
$$

Note that no restrictions have been placed upon the form of $\mathrm{G}_{\mathrm{i}}(\mathrm{t})$. It may be a simple exponential or Weibull type distribution, a bimodal distribution, or indeed any other type. Introducing the above expression for $F_{X_{i}}(t)$ in the cumulative distribution function for component failure you find

$$
F_{X}(t)=1-\prod_{i=1}^{k}\left(1-G_{j}(t)\right)^{N_{i}}
$$

The above formula for $F_{X i}(t)$ could also be derived in a slightly different manner. Considering a single flaw type, $i$, it is reasonable to view each flaw as chosen from the flaw lifetime distribution $\mathrm{G}_{\mathrm{i}}(\mathrm{t})$. In effect we have a number, $\mathrm{N}_{\mathrm{i}}$, of statistically independent competing risks.

The probability of no failures in time $t$ is

$$
R_{i}(t)=P\left(X_{i}>t\right)=1-F_{X_{i}}(t)=\left(1-G_{i}(t)\right)^{N_{i}}
$$

as before.

Component lifetime distributions with a single failure mechanism

We will first consider a single flaw type or failure mechanism in a component. The first case study illustrates this situation.

Case study 1

In a study of CMOS/SOS arrays, accelerated stress tests have been used to assess device reliability (Dugan, 1987). The devices are stressed at $200^{\circ} \mathrm{C}$ and DC-bias is applied. The principal failure mechanism is reported as being time dependent dielectric breakdown, i.e. oxide failures.

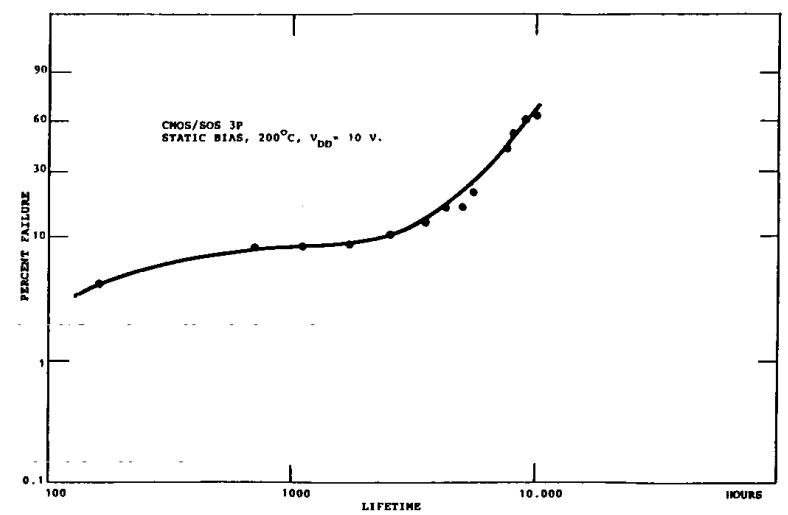

Fig. 6. Weibull plot of CMOS/SOS failures. One failure mechanism.
Figure 6 shows an illustration adapted from this study. One possible and likely interpretation of this graph is that we are looking at a mixed distribution with $8-9 \%$ early failures. This is very high, but can be attributed to the fact that the device was manufactured in what was a developing technology at the time.

In the "corresponding" example we will assume that the number of flaws, $\mathrm{N}$, in each component is the same. As shown above, the distribution of the first order statistic of the shortest lifetimes in a sample of size $N$ is

$$
F_{X}(t)=1-(1-G(t))^{N}
$$

As an example let the flaw lifetime distribution be described by a two-fold mixed Weibull distribution with the following parameters

$$
p=0.05 \%, \quad \beta_{1}=3, \quad n_{1}=10.000 h, \beta_{2}=6, \quad n_{2}=200.000 h
$$

and let $N=10$. This is probably an unrealistically large number if only "fatal" flaws are considered, i.e. those flaws that kill the component in its early or in its useful life period. On the other hand, it must be considered a small number if all, even the smallest, flaws are counted (Glaser and Subak-Sharpe, 1977; Laneuville et.al., 1985). It may be shown that for $\mathrm{N} \rightarrow \infty$ the distribution function may be written (Lloyd and Lipow, 1962)

$$
F_{X}(t)=1-\exp (-N G(t))
$$

Example 1

Using formula (3) for $\mathrm{F}_{\mathrm{X}}(\mathrm{t})$, the component lifetime distribution shown in Figure 7 can be computed. The distribution is clearly bimodal, reflecting the bimodality of the flaw distribution. The proportion of early failures is the area under the first subdistribution. It can be read off on the Weibull graph as the value of $F_{X}(t)$ where the curve levels off, i.e. $P C=0.5 \%$. It may in this example also be computed from our knowledge of the proportion of flaws in the weak subpopulation:

$$
\begin{aligned}
& \mathrm{PC}=1-(1-\mathrm{p})^{\mathrm{N}}=\mathrm{PN} \text { for } \mathrm{pN} \ll 1 \\
& \mathrm{PC}=0.05 \times 10 \%=0.5 \%
\end{aligned}
$$

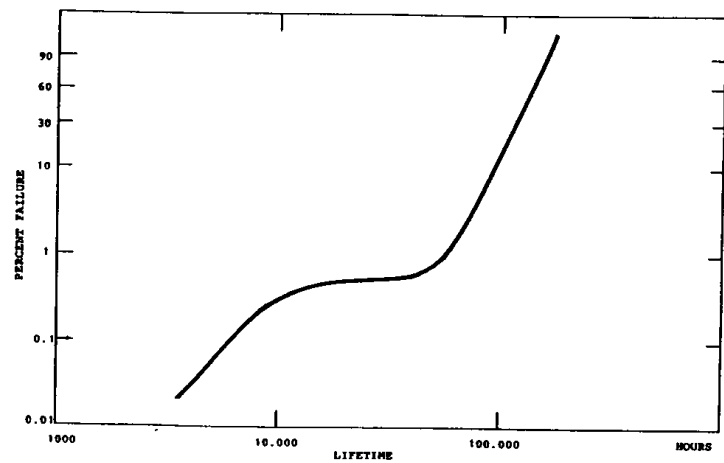

Fig. 7. Bimodal component lifetime pattern with one failure mechanism only. Percentage of freak failures is evaluated from the flat part of the curve, i.e. $\mathrm{PC}=0.5 \%$.

The failures in early life described by the separate subpopulations in the example and case study above are called freak failures. They are due to a subpopulation of fairly large flaws inherent in the component at the time of manufacture. Such freak failures can be screened out at the component level, although ideally the root cause of the problem, i.e. the generation of fatal flaws, should be resolved on the component manufacturer's production line as indeed it often is. 
Component lifetime distributions with several failure mechanisms

Let us next consider the case in which several flaw types and associated failure mechanisms are present. The situation is the one shown in Figure 5. The interesting question to ask is what will the lifetime pattern at the component level look like? This will of course depend on the distribution of the shortest lifetimes of the individual and independent failure mechanisms.

The formula for computing the lifetime pattern at the component level is (2):

$$
F_{X}(t)=1-\prod_{i=1}^{k}\left(1-G_{i}(t)\right)^{N_{i}}
$$

It is natural to expect a fairly large variety of failure patterns when different component failure mechanisms mix together. This is only true to a certain extent, however, as there seems to be some commonality in the overall failure patterns that are seen in practice. The general failure distribution for non-screened components is typically described by an early population of freak failures at the one end, and a population of long term wearout failures at the other end. In between, the tails of the different freak failure distributions intermingle with one another, and pussibiy aiso with any low tail end of long-term wearout failures. This "grey" area, of ten extending over many years or tens of years under normal operating conditions, is traditionally called the useful life period. Overall, the lifetime pattern will resemble the traditional "bathtub"Curve, or the "roller-codster" curve introduced by Wong and Lindstrom (Wong and Lindstrom, 1988).

It is often convenient for computational purposes to regard the hazard rate in the useful life period as being constant. This leads to the exponential distribution for the reliability function itself and it is the basis for all predictive techniques such as described e.g. by MIL-HDBK217 or CNET. It should be recognized, however, that for well designed and well manufactured components operating in a controlled environment, it is quite conceiveable that the hazard rate is actually zero over a period of time.

The following case study and examples illustrate some typical patterns of component failure where more than one failure mechanism is involved.

\section{Case study 2}

A series of life testing experiments on integrated circuits in plastic packages is reported by Dodson, 1979. Table shows the results from one of these lifetests in a temperature cycling environment between 25 and $125^{\circ} \mathrm{C}$ Sample size was 106, and the data represents failures of five different failure mechanisms. Only one failure mechanism exhibited a pattern corresponding to a mixed distribution. The Weibull plot of the component data is shown as Figure 8 which clearly indicates that a mixed distribution also exists at the component level.

Table 1. Results from lifetesting of integrated circuits

\begin{tabular}{cc}
\hline $\begin{array}{c}\text { Lifetime } \\
{[\text { cycles] }}\end{array}$ & $\begin{array}{c}\text { Median rank } \\
{[\%]}\end{array}$ \\
\hline 100 & 0.9 \\
200 & 2.8 \\
500 & 3.8 \\
1000 & 4.7 \\
1500 & 6.6 \\
2000 & 9.4 \\
4000 & 28.2 \\
8000 & 68.7 \\
10000 & 79.7 \\
20000 & 83.0 \\
\hline
\end{tabular}

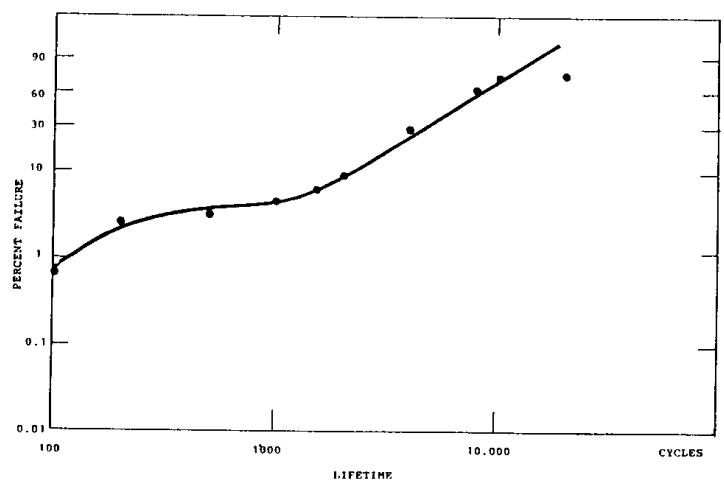

Fig. 8. Weibull plot of lifetest on plastic encapsulated integrated circuit using temperature cycling between 25 and $125^{\circ} \mathrm{C}$. Five failure mechanisms.

\section{Example 2}

The failure pattern of the integrated circuit in the case study above can easily be modelled using formula (2). The distributions of the individual failure mechanisms, $G_{i}(t)$, are specified as Weibull distributions with shape parameters and characteristic lifetimes gleaned from the study in the reference (Dodson, 1979). Only one of the failure mechanisms is given a mixed Weibull distribution. The choice of the number of flaws of each kind, $\mathrm{N}_{\mathrm{i}}$, must necessarily be somewhat arbitrary. The value $\mathrm{N}_{\mathrm{i}}=5, \mathrm{i}=1, \ldots$, 5 , is chosen for the computations.

Figures 9 and 10 show the computed failure patterns. Evidently, the Weibull plot is very much the same as for the case study. The plot of component hazard rate shows a

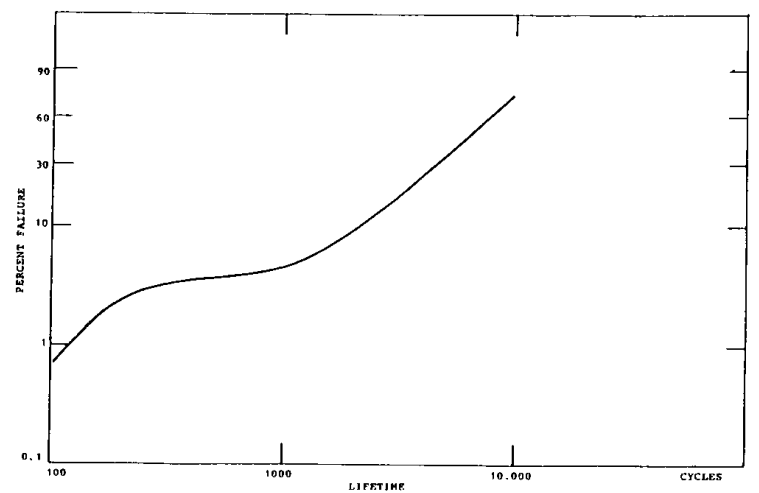

Fig. 9. Computed Weibull plot of component failures with five failure mechanisms with lifetime properties similar to case study 2 .

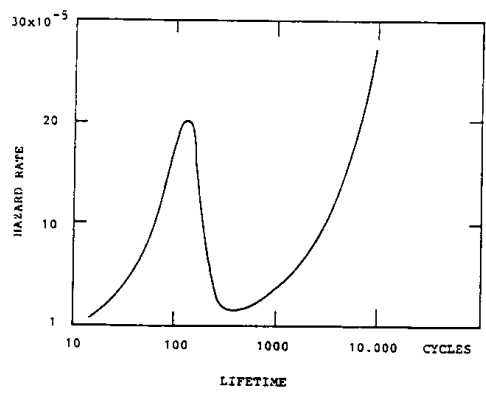

Fig. 10. Hazard rate curve for Example 2. 
distinct hump of early, freak failures, and only a very short useful life period before entering end-of-life or long-term wearout. The short useful life period reflects the rather severe temperature cycling conditions of the lifetest.

The following example illustrates the failure pattern of a component having four different failure mechanisms, each with an early failure distribution well separated from its neighbour.

\section{Example 3}

The distributions of each failure mechanism are defined as two-fold mixed Weibull distributions with the parameters shown below:

$\begin{array}{ccrrrrr}\text { Failure mechanism } & \beta_{1} & n_{1}[h] & \beta_{2} & n_{2}[h] & p[\%] & N \\ 1 & 3 & 200 & 3 & 500.000 & 0.05 & 10 \\ 2 & 3 & 1000 & 3 & 500.000 & 0.05 & 10 \\ 3 & 3 & 5000 & 3 & 500.000 & 0.05 & 10 \\ 4 & 3 & 10.000 & 3 & 500.000 & 0.05 & 10\end{array}$

Figures 11 and 12 give the failure patterns for this component. The hazard rate in Figure 12 shows a distinct "roller-coaster" type of behaviour.

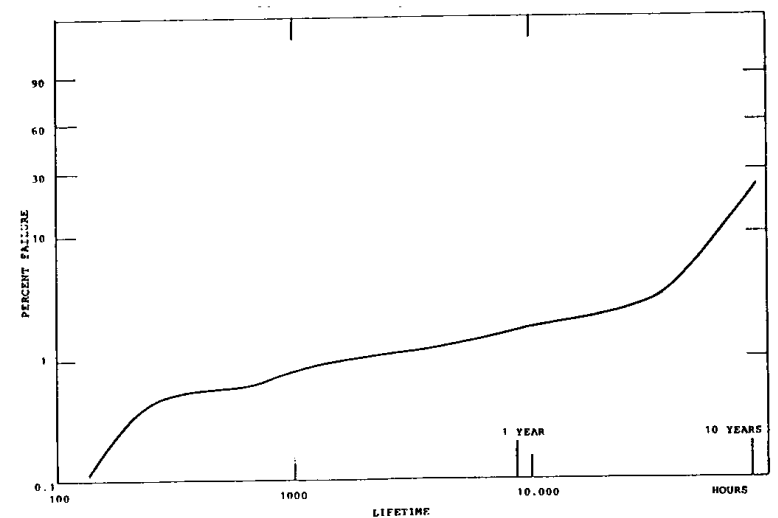

Fig. 11. Weibull plot for Example 3. Five failure mechanisms.

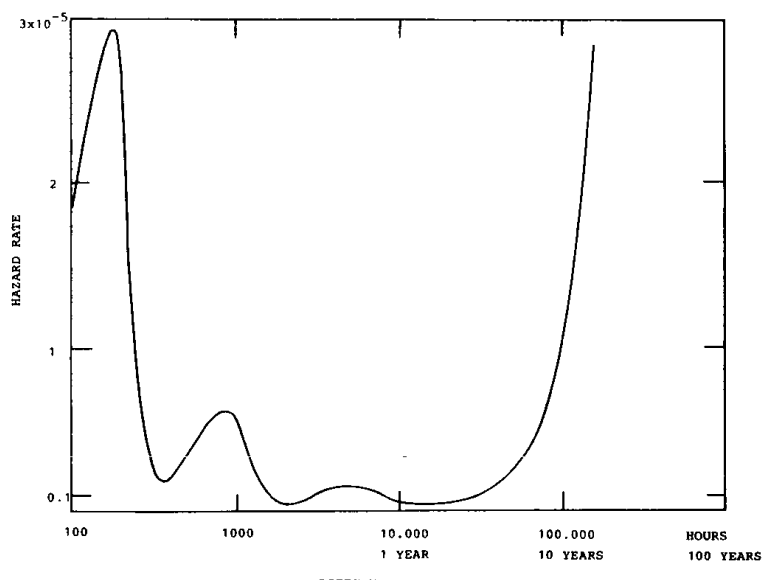

Fig. 12. The "roller-coaster" hazard rate curve of Example 3. Five failure mechanisms.

\section{Conclusions}

The modelling approach suggested in this paper is a realistic way of looking at the problems of why components fail, and of describing the types of failure pattern that are found in real life. The ability of the model to represent real life situations does not, of course, in itself constitute proof of the model as such. However, because of the model's flexibility and its close connection to component physics of failure, it is offered as a useful model for reliability engineers who need a realistic tool in analyzing and understanding component failure behaviour.

\section{$\underline{\text { References }}$}

1. Bosch, G., "Model for failure rate curves", Microelectronics and Reliability, Vol. 19, pp 371-371, 1979.

2. Carter, A.D.S., "Mechanical reliability by design", Quality and Reliability Engineering International, Vol. 2, Pp 7-18, 1986.

3. Dodson, G.A., "Analysis of accelerated temperature cycle test data containing different failure modes", 17th Annual Proceedings Reliability Physics, pp 238-246, 1979.

4. Doyle, E., Jr, and Morris, B. (eds), "Microelectronic failure analysis techniques, a procedural guide". RADC, 1982.

5. ESS, "Environmental Stress Screening Guidelines for Parts", Institute of Environmental Sciences, September 1985.

6. Gerling, W., "Factors contributing to early life reliability", NATO Advanced Research Workshop on Semiconductor Device Reliability, Helsingør, Denmark, 1985.

7. Glaser, A.B. and Subak-Sharpe, G.E., "Integrated circuit engineering", Addison-Wesley, Reading, Massachusetts, 1977.

8. Intel, "Component quarity/reliability handbook", Intel Corporation, 1986.

9. Jensen, F., Kjærgaard, C., Møltoft, J., and Rimestad, L., Field-failure study report. To be published 1989.

10. Kapur, K.C., and Lamberson, L.R., "Reliability in engineering design", John Wiley and Sons, Inc., 1977.

11. Laneuville, J., Marcoux, J., Orchard-Webb, J., and Comeau, A., "Defect characterization of silicon gate CMOS process", Semiconductor International, pp 250-254, May 1985

12. Loyd, D.K. and Lipow, M., "Reliability: Management, methods, and mathematics", Prentice-Hall International, 1962.

13. Mann, N.R., Schafer, R.E., and Singpurwalla, N.D., "Methods for Statistical Analysis of Reliability and Life Data", John Wiley and Sons, New York, 1974.

14. Mead, P.H., "Reliability growth of electronic equipment", Microelectronics and Reliability, Vol. 14, PP 439-443, 1975.

15. Nash, F.R. et. al., "Selection of a laser reliability assurance strategy for a long-life application", AT\&T Technical Journal, Vol. 64, No. 3, pp 671-675, March 1985.

16. Pitetti, R.C., "Electromigration of TiPdAu conductors", Proceedings of 10th Annual Reliability Physics, pp $171-174,1972$.

17. Wong, K.L., and Lindstrom, D.L., "Off the bathtub onto the roller-coaster curve". Annual Reliability and Maintainability Symposium Proceedings, pp 356-363, 1988.

\section{Biography}

Finn Jensen is a graduate of the Technical University of Denmark with a Ph.D. in electronics engineering. Dr. Jensen spent four years working in industry before becoming an independent reliability consultant in 1974. Concurrent with his consulting, Dr. Jensen has, since 1976, been involved in a number of government sponsored research projects at the Engineering Academy of Denmark. Since 1981 he has presented reliability courses world-wide for the continuing engineering education programme of the George Washington University, U.S.A. Dr. Jensen has co-authored two books in the field of reliability engineering, and he was in 1983 appointed Chief Editor of the journal Quality and Reliability Engineering International. 